\title{
Damage Simulation Analysis of Discrete Rods to SAM based on FEA
}

\author{
WANG Chengcheng $^{1, a}$, XIE Xiaofang ${ }^{1}$, QIAO Yongjun ${ }^{1}$ and LIU Jiaqi ${ }^{1}$ \\ ${ }^{1}$ NAEl, YanTai, ShanDong, China
}

\begin{abstract}
At present ship to air missile is the main force of anti-missile. The warhead damage element' impact and penetration effect are the main factors for damaging supersonic anti-ship missile (SAM). In this paper, the damage mechanism of the anti-ship missile is studied. Dynamic initial velocity of damage elements is modeled and simulated. The four important parts of SAM with typical material are modeled and simulated based on finite element analysis (FEA). It's useful to the study of the further model of vulnerability analysis of whole anti-ship missiles.
\end{abstract}

\section{Introduction}

Anti-ship missiles(ASM), with small size, fast velocity, changeable trajectory, have caused great difficulties for the defense counterattack. Short-range anti-ballistic missile is the last bulwark of our military ships to face the enemy missile attack. The importance and urgency of its development is self-evident. With the launching of the aircraft carrier, it's mentioned in a very high degree.

As the restriction of the guidance accuracy and target maneuver, direct hit probability of ship to air missile to anti-ship missile is low. In most cases proximity fuze and warhead mutilate element (fragment or discrete rod) are used to intercept $\operatorname{ASM}(1,2$ and 3$)$, which involves the fuze-warhead coordination and the warheads mutilate ability.

\section{The Damage Mechanism}

The damage effect indicators should generally be based on the target characteristics, damage mechanism, and combined with the operational intent select.

Damage mechanism of the components is related to the damage units. For example, the hit and penetration of fragment damage units may make partial or complete loss of component function, weaken the structural strength, ignite or detonate the flammable and explosive components, while the shock wave may make the structural damage of the target.

Ship to air missile general uses the radio proximity fuze, working according to the principle of the Doppler effect $(4,5)$. When the damage elements reach close to the scheduled distance to the missile, they are detonated. A large number of high-velocity fragments or discrete rods are made after the explosion. After hitting the missile target, some fragments or discrete rods penetrate missile skin, damaging the important parts of the missile, making

\footnotetext{
a Corresponding author: 497990518@qq.com
}

the missile out of control and deviate from the scheduled trajectory even explosion, etc..

A certain type of anti-ship missile is divided into three compartments: the fairing cabin, warhead cabin and engine cabin(6). According to the basic components and functions of the main components of internal systems of the cabins, combined with typical missile to be hit by the various damage modes, the four systems are taken as the objects of study to go on with damage analysis.

\section{Dynamic Velocity Attenuation Model of Damage Elements}

Dynamic initial velocity of damage elements after the warhead of ship to air missile exploded is

$$
v_{f}\left(\phi_{d}\right)=\left(v_{l}^{2}+v_{m}^{2}+2 v_{l} v_{m} \cos \phi_{l}\right)^{0.5}
$$

Type: $\phi_{l}$ is static flying angle of discrete rods, $v_{m}$ is the velocity of ship to air missile, $v_{l}$ is the static flying velocity, $\phi_{d}$ is dynamic flying angle of discrete rods,

Gurney formula(7,8) is commonly used for integral warheads to calculate the static flying velocity of damage element. for the cylinder charge, fragment velocity $v_{p}$ is

$$
v_{p}=\sqrt{2 E} \sqrt{\frac{M_{z} / M_{k}}{1+0.5 M_{z} / M_{k}}}
$$

Type, $\sqrt{2 E}$ is a Gurney constant, $\mathrm{E}$ is the ratio of explosives, $M_{z}$ and $M_{k}$ are respectively for the unit length of cylinder explosive quality and the quality of the warhead shell.

It is the assumption for the convenience of modeling: 
1) The discrete rod is as a rigid body, not considering bar structure deformation in the process of flying;

2) Ignore the interaction between discrete rods in the process of flying;

Ignore the influence of gravity, the resistance equation of the discrete rods' movement are:

$$
F=0.5 C_{l} \rho S_{l} v_{f}^{2}
$$

Type: $C_{l}$ is air resistance coefficient of the discrete rods; $\rho$ is atmospheric density, $S_{l}$ is the bar area in the breeze.

Active warhead fragments are generally divided into spherical, diamond, oblong, prisms, etc.. Discrete rod belongs to a special form of fragment. For fragment velocity attenuation equation, most of the existing literatures(9) use air drag coefficient $C_{l}$ as constant term in the calculation. In fact $C_{l}$ is closely related to the fragment flying velocity and body shape. The prism model fragment, meets the following formula:

$$
C_{l}=A_{1}+A_{2} \cdot\left(c_{s} / v_{f}\right)-A_{3} \cdot\left(c_{s} / v_{f}\right)^{2}
$$

Type: $c_{s}$ is the velocity of sound; $A_{1}, A_{2}, A_{3}$ are constants. It is not hard to see, as the bar flying velocity attenuation, values of $C_{l}$ have significant changes. It will inevitably cause large error by using the fixed value.

On the basis of the type, the discrete rod velocity attenuation equation is solved. According to the law of Newton, the differential equation of discrete rods velocity $v_{f}$ to athletic time $t$ is:

$$
m_{l} \frac{d v_{f}(t)}{d t}=-\frac{1}{2} C_{l} \rho S_{f} v_{f}^{2}(t)
$$

By type(5-17) (5-19)differential equation of discrete rods velocity can be obtained:

$$
\begin{gathered}
\frac{d v_{f}(t)}{d t}=-0.5 \rho \phi_{l} m_{l}^{-1 / 3}\left[A_{1} \cdot v_{f}^{2}(t)+A_{2} \cdot c_{s} v_{f}(t)-A_{3} \cdot c_{s}^{2}\right] \\
\text { Set } M=0.5 A_{1} \rho \phi_{l} m_{l}^{-1 / 3}, N=0.5 A_{2} \rho \phi_{l} m_{l}^{-1 / 3} c_{s}, \\
P=0.5 A_{3} \rho \phi_{l} m_{l}^{-1 / 3} c_{s}^{2}, \text { if initial dynamic velocity of }
\end{gathered}
$$
discrete rods is known as $v_{f}(0)=v_{f 0}$, discrete rods velocity $v_{f}$ with flying time $t$ attenuation analytical solutions can be obtained:

$$
\begin{aligned}
& v_{f}(t)=\frac{Q}{2 M} \tanh \left[Q \cdot t+\operatorname{arctanh}\left(\frac{2 M v_{f 0}+N}{Q}\right)\right]-\frac{N}{2 M} \\
& \text { Type: } Q=0.5\left(4 A_{1} A_{3}+A_{2}^{2}\right)^{0.5} \rho \phi_{l} m_{l}^{-1 / 3} c_{s} .
\end{aligned}
$$

\section{Damage numerical simulation of discrete rods to SAM}

Ship to air missile can cause damage to ASM in relatively long range. This section is mainly damage modeling and simulation analysis of discrete rods to SAM. In this paper, ANSYS/LS-DYNA finite element analysis software is used to analyze that the discrete rods penetrate SAM.

\subsection{The initial simulation conditions}

After the warheads exploded, the spread of discrete rods forms a cone cutting circle. In different radius of circle, the density and flying velocity of discrete rods are different. $r_{l}=8 m$ is selected as the damage radius of discrete rods.

1) Dynamic velocity of discrete rods

Suppose in explosion instant of warhead, the velocity of ship to air missile is $800 \mathrm{~m} / \mathrm{s}$. Initial static velocity of discrete rods of ship to air missile is $2000 \mathrm{~m} / \mathrm{s}$. Static direction of bars along the missile longitudinal axis is $90^{\circ}$. The velocity of SAM is $850 \mathrm{~m} / \mathrm{s}$. The velocity vectors are parallel to each other. According to the discrete rods flying velocity attenuation calculation, the dynamic instantaneous velocity of discrete rods after flying $8 \mathrm{~m}$ is: $v_{f}=1800 \mathrm{~m} / \mathrm{s}$.

Due to the discrete rods and SAM in high velocity motion state, the discrete rods penetration process is very short. In this brief penetration process, its rotation angle is very small, which can cause little effect on the penetration performance. To simplify the analysis, discrete rods are set no additional angular velocity component in the simulation.

Table1 Main material parameters

\begin{tabular}{|l|l|l|l|l|l|l|l|}
\hline $\begin{array}{l}\text { Materia } \\
\text { paramet } \\
\text { ers }\end{array}$ & $\begin{array}{l}\rho_{/ /(g / c} \\
\left.m^{3}\right)\end{array}$ & $\begin{array}{l}\mathrm{G} / \mathrm{G} \\
\mathrm{Pa}\end{array}$ & $\begin{array}{l}\mathrm{A} / \mathrm{G} \\
\mathrm{Pa}\end{array}$ & $\begin{array}{l}\mathrm{B} / \mathrm{G} \\
\mathrm{Pa}\end{array}$ & $\mathrm{n}$ & $\mathrm{C}$ & $\mathrm{m}$ \\
\hline $\begin{array}{l}4340 \\
\text { steel }\end{array}$ & 7.83 & 77 & $\begin{array}{l}0.79 \\
2\end{array}$ & $\begin{array}{l}0.51 \\
0\end{array}$ & $\begin{array}{l}0.2 \\
6\end{array}$ & $\begin{array}{l}0.01 \\
4\end{array}$ & $\begin{array}{l}1.0 \\
3\end{array}$ \\
\hline $\begin{array}{l}\text { Titaniu } \\
\text { m alloy }\end{array}$ & 4.5 & 44 & $\begin{array}{l}1.09 \\
8\end{array}$ & $\begin{array}{l}1.09 \\
2\end{array}$ & $\begin{array}{l}0.9 \\
3\end{array}$ & $\begin{array}{l}0.01 \\
4\end{array}$ & 1.1 \\
\hline $\begin{array}{l}\text { Hard } \\
\text { aluminu } \\
\text { m }\end{array}$ & 2.77 & 28.6 & $\begin{array}{l}0.36 \\
9\end{array}$ & $\begin{array}{l}0.68 \\
4\end{array}$ & $\begin{array}{l}0.7 \\
3\end{array}$ & $\begin{array}{l}0.00 \\
83\end{array}$ & 1.7 \\
\hline $\begin{array}{l}\text { Tungste } \\
\mathrm{n} \text { alloy }\end{array}$ & 17.6 & 137 & 1.51 & $\begin{array}{l}0.17 \\
7\end{array}$ & $\begin{array}{l}0.1 \\
2\end{array}$ & $\begin{array}{l}0.01 \\
6\end{array}$ & 1.0 \\
\hline
\end{tabular}

Lagrangian solid element is used in the calculation to divide the mesh. The target plate boundary is constrained and fixed. Erosion and contact-dynamic algorithms are used to achieve interaction of projectile and tank shell. In process of geometric discrete, as far as possible to ensure uniform of the airframe grid size.

\subsection{Penetrating simulation analysis}

To test and verify the damage capability of ship to air missile to typical SAM in the suppose damage radius, the 
penetration of discrete rods to the four parts of SAM is simulated and analyzed.

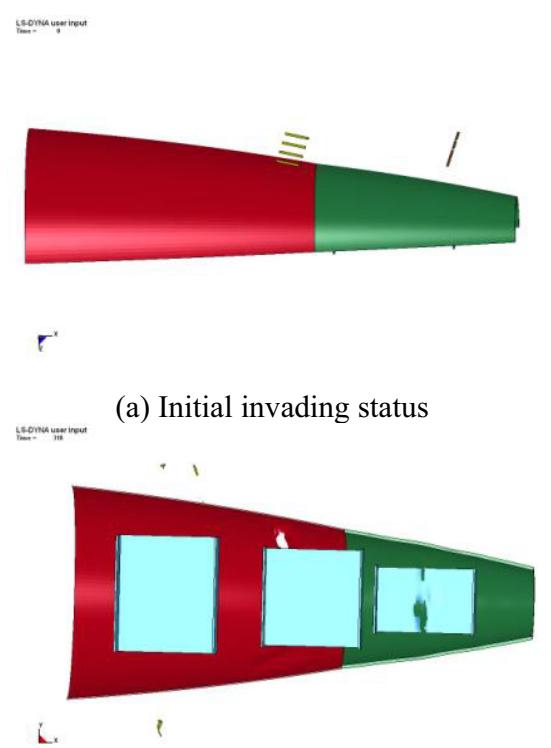

(b) Invading effect the fairing

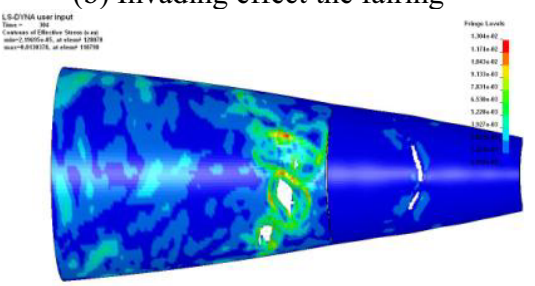

(c) Damage stress cloud picture

Fig.1 Damage status of projectile to the fairing cabin of SAM<smiles>C1[13CH]2C[14CH]12</smiles>

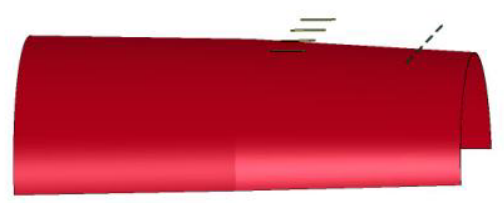

$r$

(a) Initial invading status

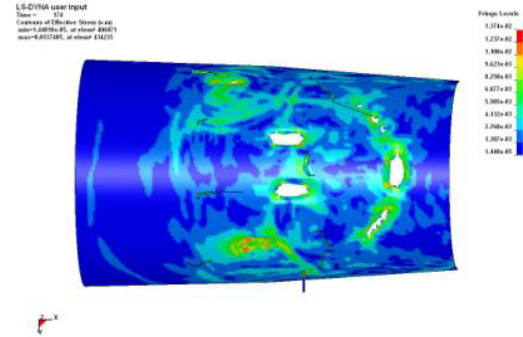

(b) Damage of warhead cabin skin

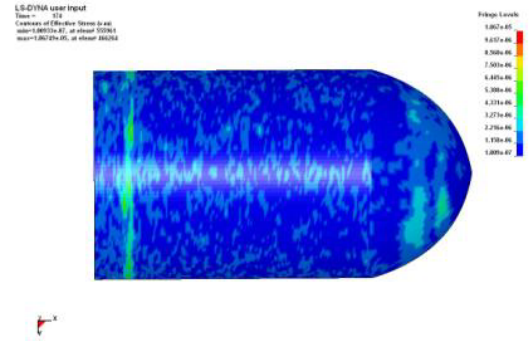

(c) Damage of warhead shell

Fig.2 Damage status of projectile to the warhead cabin of SAM
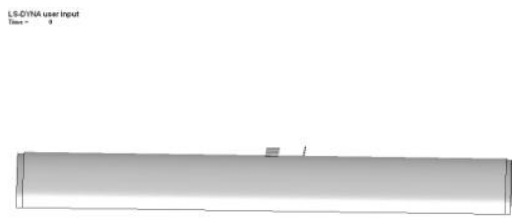

(a) Initial invading status

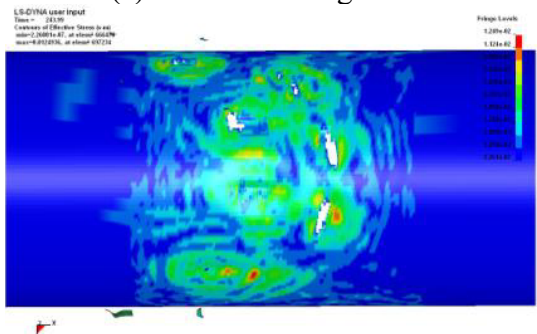

(b) Damage of engine cabin skin

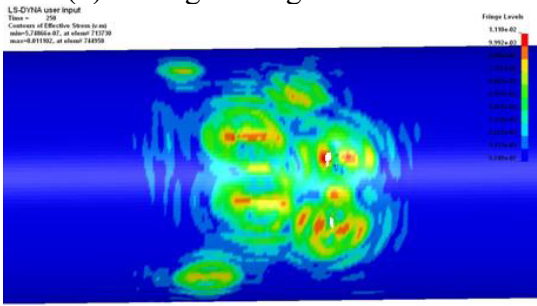

$t^{2}$

(c) Damage of engine shell

Fig.3 Damage status of projectile to the engine cabin of SAM

From the results of numerical simulation, the deformation of discrete rods occurred in the process of penetration is bigger. Bars near the edge of the module ricochet. By comparing with the numerical simulation results of the discrete rods to each segment of SAM, the following conclusion can be got.

1) The damage ability of discrete rods to each system of SAM is different. By each segment penetration analysis, under the same penetration condition, the destruction to warhead system is the weakest, the destruction to guidance and control system is the strongest.

2) Different penetration parts of the same cabin of SAM have bigger influence on the penetration effectiveness. SAM is approximate cylinder body and the numerical simulation results show that the discrete rods near the middle of the projectile of SAM skin cutting rate is 
higher, and the discrete rods near the projectile side mostly ricochet occurred after contact with skin.

3 ) The direction of the relative velocity vector has bigger influence on penetration efficiency. Under the condition of the head-on interception, when the relative velocity is known, with the increase of the velocity vector Angle, vertical longitudinal axis velocity component of the relative velocity vector of discrete rods and SAM will increase. The penetration damage efficiency of discrete rods to SAM will increase accordingly.

\section{Summary}

Overall Damage Analysis of SAM is built on the basis of analysis of the damage effect of the various systems of the missile. Te vulnerability data is dynamically changing with the missile flight environment, flight attitude and so on. The paper analyzes the damage mechanism of SAM. Dynamic initial velocity of damage elements is modeled and simulated. The four important parts of SAM with typical material are modeled and simulated based on finite element analysis (FEA). The result is credible and useful to the study of the further model of vulnerability analysis of whole anti-ship missiles.

\section{Acknowledgments}

This work was supported by China Postdoctoral Science Foundation. (No20110491883).

\section{References}

1. Zhou Jun, Wang Dehu, Feng wening.Time-fuzed ammunition simulative model of hitting on the missile target[J]. Journal of Ballistics.2005.6,33-36.

2. LU Xiangjiang, LI Xiangrong, ZHANG Qingming. Damage Assessment of Missile Hit by Fragmentation Warhead[J]. Journal of Projectiles , Rocket s , Missiles and Guidance. 2008.12,83-86.

3. Zhou Zhichao.The Vulnerability Analysis and Computation of the Antiship Missile to Prefabricated Fragmentation Shell.[J]. Journal of Projectiles , Rocket s, Missiles and Guidance. 2006.1,750-752.

4. Lupoae M, Goga D, Constantin D, et al. Aspects Regarding the Water jet Propulsion Using Explosive Energy for Door Breaching[C]. Proceedings of the World Congress on Engineering, 2011: 2138-2142.

5. Gardner S E. Analysis of Fragmentation and Resulting Shrapnel Penetration of Naturally Fragmenting Cylindrical Bombs[R]. California: Lawrence Livermore National Laboratory, 2000.

6. Gupta N K, Iqbal M A, Sekhon G S. Effect of projectile nose shape, impact velocity and target thickness on the deformation behavior of lay2ered plates[J]. Int J Impact Engng, 2008,35(1):37-60.

7. Lupoae M, Goga D, Constantin D, et al. Aspects Regarding the Water jet Propulsion Using Explosive Energy for Door Breaching[C]. Proceedings of the World Congress on Engineering, 2011: 2138-2142.
8. Gardner S E. Analysis of Fragmentation and Resulting Shrapnel Penetration of Naturally Fragmenting Cylindrical Bombs[R]. California: Lawrence Livermore National Laboratory, 2000.

9. Robert E Ball. The Fundamentals of Aircraft Combat Survivability Analysis and Design[M].2nd Edition. Reston, VA: American Institute of Aeronautics Inc, 2003:603-695. 